\title{
Determination of crystal growth rates during rapid solidification of polycrystalline aluminum by nano-scale spatio-temporal resolution in situ transmission electron microscopy
}

\author{
K. Zweiacker, ${ }^{1, a)}$ J. T. McKeown, ${ }^{2}$ C. Liu, ${ }^{1}$ T. LaGrange, ${ }^{2, b)}$ B. W. Reed, ${ }^{2, c)}$ G. H. Campbell, ${ }^{2}$ \\ and J. M. K. Wiezorek ${ }^{1}$ \\ ${ }^{1}$ Department of Mechanical Engineering and Materials Science, University of Pittsburgh, 648 Benedum Hall, \\ 3700 OHara Street, Pittsburgh, Pennsylvania 15261, USA \\ ${ }^{2}$ Materials Science Division, Physical and Life Science Directorate, Lawrence Livermore National Laboratory, \\ 7000 East Avenue, Livermore, California 94551, USA
}

(Received 10 May 2016; accepted 23 July 2016; published online 4 August 2016)

\begin{abstract}
In situ investigations of rapid solidification in polycrystalline $\mathrm{Al}$ thin films were conducted using nano-scale spatio-temporal resolution dynamic transmission electron microscopy. Differences in crystal growth rates and asymmetries in melt pool development were observed as the heat extraction geometry was varied by controlling the proximity of the laser-pulse irradiation and the associated induced melt pools to the edge of the transmission electron microscopy support grid, which acts as a large heat sink. Experimental parameters have been established to maximize the reproducibility of the material response to the laser-pulse-related heating and to ensure that observations of the dynamical behavior of the metal are free from artifacts, leading to accurate interpretations and quantifiable measurements with improved precision. Interface migration rate measurements revealed solidification velocities that increased consistently from $\sim 1.3 \mathrm{~m} \mathrm{~s}^{-1}$ to $\sim 2.5 \mathrm{~m} \mathrm{~s}^{-1}$ during the rapid solidification process of the $\mathrm{Al}$ thin films. Under the influence of an additional large heat sink, increased crystal growth rates as high as $3.3 \mathrm{~m} \mathrm{~s}^{-1}$ have been measured. The in situ experiments also provided evidence for development of a partially melted, two-phase region prior to the onset of rapid solidification facilitated crystal growth. Using the experimental observations and associated measurements as benchmarks, finite-element modeling based calculations of the melt pool evolution after pulsed laser irradiation have been performed to obtain estimates of the temperature evolution in the thin films. Published by AIP Publishing.
\end{abstract}

[http://dx.doi.org/10.1063/1.4960443]

\section{INTRODUCTION}

Laser processing of metals and alloys involves extreme thermo-mechanical conditions which are exploited in technologies for thin film device modification, material joining, and additive manufacturing. During selective laser melting (SLM), the bulk material, powders, or thin-films undergo driven first-order phase transformations and the resulting micro-structures will strongly deviate from equilibrium. The photon irradiation will result in large thermal gradients of $\sim 10^{5}-10^{7} \mathrm{~K} \mathrm{~m}^{-1}$ over small timescales which will ultimately lead to rapid cooling rates of $10^{5}-10^{7} \mathrm{~K} \mathrm{~s}^{-1}$ and transformation interface velocities of $\sim 10^{-2} \mathrm{~m} \mathrm{~s}^{-1}$ to $\sim 10^{2} \mathrm{~m} \mathrm{~s}^{-1}$. ${ }^{-3}$ Under these extreme conditions, growth at solid-liquid interfaces can be essentially barrier-less, limited only by the kinetic attachment of atoms to the growing solid phase or phases. This inherent non-equilibrium process enables extraordinary micro-structural changes such as scale refinements, solid solubility limit extensions, non-equilibrium

\footnotetext{
${ }^{a}$ Present address: Empa - Swiss Federal Laboratories for Materials Science and Technology Ueberlandstrasse 129, 8600 Duebendorf, Switzerland. Electronic mail: Kai@zweiacker.org.

b) École Polytechnique Fédérale de Lausanne, Interdisciplinary Centre for Electron Microscopy, MXC 134 (Batiment MXC), Station 12, CH-1015 Lausanne.

Integrated Dynamic Electron Solutions, Pleasanton, CA 94588, USA.
}

phase formation, and even partition-less crystal growth in alloys. Hence, the growth dynamics, and the microstructures present, are scientifically interesting and technologically important. In situ transmission electron microscopy (TEM) studies of irreversible reactions in condensed matter often provide critical mechanistic understanding and measurements that can be uniquely effective to support computer model development. ${ }^{4-6}$ However, conventional TEM-based in situ studies typically offer temporal resolution in the millisecond range, which is insufficient for investigations of RS process dynamics. ${ }^{5,7}$ The dynamic transmission electron microscope (DTEM), a TEM modified by two complex laser systems, offers nano-scale spatiotemporal resolution, rendering it uniquely suited for studies of irreversible transitions in materials, including those associated with RS transformations. ${ }^{8-16}$ The DTEM uses intense electron pulses of durations as short as $15 \mathrm{~ns}$ for the acquisition of images or diffraction patterns. In its original operational mode, the DTEM was limited to acquisition of a single image or diffraction pattern at a preselected delay time after initiation of the irreversible transition event, i.e., a single-pump/single-probe mode. ${ }^{8,9,12,14}$ Hence, past DTEM studies of RS in $\mathrm{Al}$ and $\mathrm{Al}-\mathrm{Cu}$ alloys required the performance of a series of multiple, separate experiments with varied delay times in order to obtain information on the transformation 
rates. $^{8,9,12,14}$ While a single-probe pulse acquisition intrinsically offers temporal resolution on the ns-scale for each single image or diffraction pattern, the uncertainty in the transformation rates determined from a series of separate DTEM experiments can be significantly larger, involving contributions from systematic and non-systematic errors. For $\mathrm{RS}$ in $\mathrm{Al}-\mathrm{Cu}$ alloy thin films, a range of absolute error for the instantaneous solidification front velocity was reported as $\pm 0.6 \mathrm{~m} \mathrm{~s}^{-1}$, representing a relative error of about $30 \%$ for a $2 \mathrm{~m} \mathrm{~s}^{-1}$ transformation rate measurement. ${ }^{14}$ Sources of error include the $\sim 5 \%$ pulse-to-pulse fluence fluctuations of the specimen-drive-laser system that delivers the heating pulse to the specimen, and reflectivity variations from microstructure differences, e.g., grain size and surface roughness, between the multiple specimens used in single-pump/singleprobe mode DTEM in situ studies, which may affect small variations in the initial melt pool dimensions. Furthermore, prior DTEM RS studies used a small field of view for locally resolved observations of small sections or segments of the evolving melt pool boundary. $8,9,12,14$ Thus, determination of the transformation interface velocity required reliance on assumptions regarding the melt pool size and shape with relatively large inherent uncertainty, further challenging the reliability of the reported transformation rates. ${ }^{8,14}$

Recent upgrades of the DTEM instrumentation have successfully enabled single-pump/multiple-probe operation for acquisition of multiple images or diffraction patterns per each transformation event triggered by the pulsed-laser irradiation. ${ }^{15,17,18}$ In this operational mode, termed Movie Mode DTEM (MM-DTEM), the laser-pulse-driven photoelectron cathode of the modified instrument can provide electron pulse trains, permitting acquisition of up to nine (9) frames of images or diffraction patterns per single-shot stimulated dynamic event within as little as $\sim 1 \mu \mathrm{s}$. ${ }^{17}$ This is equivalent to a frame rate $\sim 10^{6}$ times higher than those of conventional tv-rate in situ TEM experiments. Compared with prior in situ DTEM studies using the single-pump/single-probe operational mode, ${ }^{8,11,13,14,16,18}$ the MM-DTEM experiments offer potential to greatly reduce uncertainties in quantitative measurements of transformation front velocity evolution during RS and increase significantly the data density obtained from direct observations of the dynamics of the irreversible transformation event induced by a single laser pulse. ${ }^{15,17}$ The current paper reports and discusses first results of MM-DTEM in situ investigations of the dynamics of pulsed-laser-induced melting and RS in $160 \mathrm{~nm}$ thick Al thin films with a focus on establishing experimental methodology for reproducible quantitative measurements of the transformation rates. Specifically, we assessed the effects from the Si frame support of the window-type TEM grids used in the DTEM in situ experiments on the solidification velocity measurements. Compared to the regions of the thin film specimen in the electron transparent window, the Si frame support represents a massive heat sink and can alter the thermal transport geometry significantly. Monitoring of entire melt pools during the in situ experiments permitted measurement of location-specific differences in the interface migration rates during RS, which involved directional growth of columnar crystals and was facilitated by thermally driven migration of morphologically planar solidification interface segments at rates as high as $\sim 3.3 \mathrm{~m} \mathrm{~s}^{-1}$. Evidence for development of a partially melted, two-phase region during the initial stages after laser irradiation has been detected. Multi-physics-based computer numerical modeling of the melt pool size and shape changes, and associated transformation rate calculations enabled calculation of the thermal field evolution and confirmed the dominance of essentially two-dimensional, planar thermal transport during the RS of the Al thin films.

\section{EXPERIMENTAL PROCEDURES AND MATERIALS}

Polycrystalline Al thin films, $160 \mathrm{~nm}$ thick, were deposited on $50 \mathrm{~nm}$ thick amorphous $\mathrm{Si}_{3} \mathrm{~N}_{4}$ membranes of commercially available windowed TEM grids (Ted Pella) by electron beam evaporation. During depositions using 99.999\% purity $\mathrm{Al}$ as source material, the chamber pressure and substrate temperature were kept below $5 \times 10^{-8}$ Torr and at $298 \mathrm{~K}$, respectively. Thus, specimens suitable for in situ DTEM experimentation with electron transparent, square-shaped areas of $0.5 \mathrm{~mm} \times 0.5 \mathrm{~mm}$ dimensions have been obtained, as shown schematically in Figs. 1(a) and 1(b). Further details of the specimen preparation have been reported previously. ${ }^{13,14,16,19}$ Notably here, unlike in prior reports, no capping layers have been deposited on the $\mathrm{Al}$ layer. ${ }^{8,11,20,21}$ Regions of the TEM grid sample adjacent to the electron transparent region are supported by a substrate of Si. Relative to solid Al, the thermal conductivity of amorphous $\mathrm{Si}_{3} \mathrm{~N}_{4}$ is about twenty times smaller, while that of solid $\mathrm{Si}$ is comparable. ${ }^{22,23}$ Also, within about $1 \mu \mathrm{m}$ from the edge of the electron transparent window, the $\mathrm{Si}$ substrate frame thickness reaches about $1.4 \mu \mathrm{m}$ (Fig. 1(a)). Therefore, it is necessary to evaluate the possible effects of the Si frame acting as an effective heat sink on the transformation dynamics in order to ensure that reliable solidification interface velocity measurements are obtained from in situ DTEM experiments using the TEM grid-based specimens. Hence, nominally identical MM-DTEM experiments have been performed for five different locations with systematically varied distances, $\Delta x$, in the range of $50 \mu \mathrm{m} \leq \Delta x \leq 250 \mu \mathrm{m}$, from the edge of the electron transparent window, as indicated schematically in Fig. 1(b). In situ TEM experiments were performed with the DTEM at Lawrence Livermore National Laboratory ${ }^{15,17}$ where an Nd-YAG laser produces a single, $12 \mathrm{~ns}$ duration pulse with a primary wavelength of $1064 \mathrm{~nm}$ and a Gaussian beam profile in order to stimulate transformations in the specimen. Laser pulses delivering a total of $\sim 72 \mu \mathrm{J}$ to the specimen in the DTEM column provided photon stimuli to initiate the melting of the Al film (Figs. 1(a) and 1(b)). Pulse-to-pulse energy fluctuations of 5\% have been determined for the Nd-YAG laser. The heating laser pulse is incident at an angle of $\sim 45^{\circ}$, producing elliptically shaped irradiation cross-sections with the thin film sample, as shown schematically by the superimposed intensity profiles with ISO-intensity lines ranging from 100 (red) to $13.5 \%$ or $\sim 1 / \mathrm{e} 2$ (gray) of peak fluence for location (1) in Fig. 1(b). Nominally identical laser pulses were placed on the electron transparent region of the $\mathrm{Al}$ thin film specimens at different locations with systematically varied distances $\Delta x$ 
a) TEM Sample Setup

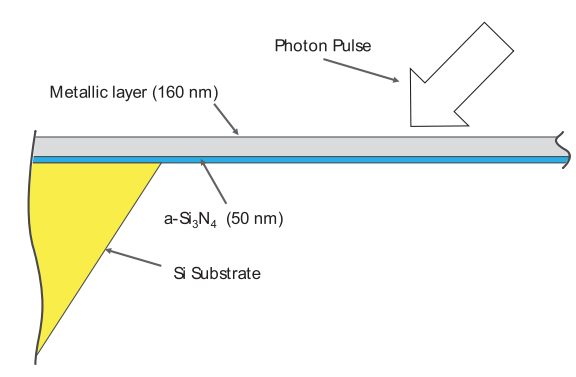

c) Observational Window $\sim 20 \mu \mathrm{s}$

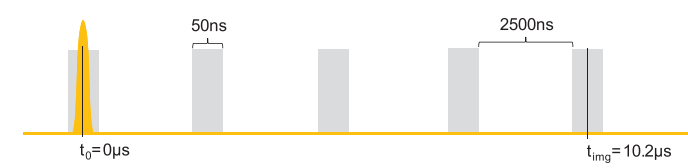

from the edge of the $\mathrm{Si}$ substrate support frame as marked by the labels (1) to (5) in Fig. 1(b), in order to determine the effect of $\Delta x$ on the phase transformation dynamics. The distances $\Delta x$ have been measured from the center of the incident pulsed laser irradiation as the shortest distances to the edge of the electron transparent window (e.g., location marked by label 3 at $\Delta x=100 \mu \mathrm{m}$, Fig. 1(b)). The MMDTEM electron pulse train selected for the in situ experiments performed here, illustrated schematically in Fig. 1(c), enabled observation of the entire melting and subsequent solidification sequence and minimized effects from motion blur while maximizing image contrast in each frame. Each experiment delivered nine $50 \mathrm{~ns}$ exposure-time image frames, collected with an inter-frame delay of $2.5 \mu$ s during the $20.4 \mu$ s total time interval of observation (Fig. 1(c)). The peak of the Gaussian sample-modifying laser pulse is referenced as time $t_{0}$, with the first frame set to $t_{0}$ and each subsequent frame collected at time $t_{\text {img }}=t_{0}+\Delta t$, i.e., at a time delay $\Delta \mathrm{t}$ after $\mathrm{t}_{0}$ (Fig. 1(c)). The temporal resolution is therefore $50 \mathrm{~ns}$ for each individual frame, while temporal resolution for transformation dynamics observations is limited by the $2.55 \mu$ s inter-frame delay time of the electron pulse train (Fig. 1(c)). The image series have been recorded as laterally displaced individual images by using an electrostatic deflector system that translates each frame to a different segment of a $2 \mathrm{k} \times 2 \mathrm{k}$ charged-coupled device (CCD) camera with single-electron detection sensitivity. ${ }^{15,17}$ Post-acquisition image processing and analysis have been performed using the ImageJ(Fiji) software (NIH, http://imagej.nih.gov/ij/) environment in order to determine quantitatively the area of liquid $\mathrm{Al}$ in the DTEM BF images. For the regular elliptical shape melt pool area, measurements of the radii along the major and minor axes, $r_{\max }$ and $r_{\min }$, as well as that of $\mathrm{r}$, the geometric-mean radius, representing the radius of circular area equivalent in size to the actual melt pool area have been obtained for each DTEM BF image. The radii have been determined with an absolute error range no worse than six (6) pixels from the DTEM BF images, corresponding to $\approx \pm 500 \mathrm{~nm}$. Motion blur in a $50 \mathrm{~ns}$ exposure $\mathrm{BF}$ image of the
MM-DTEM series for a solid-liquid interface migrating at a rate of $1 \mathrm{~m} \mathrm{~s}^{-1}$ limits the spatial resolution to $50 \mathrm{~nm}$ and is not a limiting factor for the determination of the transformation interface velocities from the temporal evolution of the respective melt pool radii.

A JEOL JEM 2100F TEM instrument equipped with a device (ASTAR/DigiSTAR, NanoMEGAS) for precession electron diffraction (PED)-based automated crystal orientation mapping (ACOM) has been used for the microstructure analysis of the films..$^{20,24}$ The PED-based ACOM has been performed with $200 \mathrm{kV}$ electrons, $0.6^{\circ}$ precession half-angle, $2 \mathrm{~nm}$ probe size, and $10 \mathrm{~nm}$ step size on typically $1.5 \mu \mathrm{m} \times 1.5 \mu \mathrm{m}$ to $2 \mu \mathrm{m} \times 2 \mu \mathrm{m}$ area scans. ${ }^{20,24}$

Multi-physics finite element modeling has been performed in the $\mathrm{COMSOL}^{\mathrm{TM}}$ (version 5.1, COMSOL, Inc.) software environment using a modified enthalpy model, which solves the Stefan problem by adopting the enthalpy density as the dependent variable, for calculations of temperature evolution in the thin film sample after delivery of a laser pulse. ${ }^{25,26}$ The Gaussian laser pulse profile characteristics used in the model calculations were constrained to the experimentally utilized parameters regarding the elliptical shape and size on the sample, e.g., diameters of $\sim 135 \mu \mathrm{m}$ and $\sim 190 \mu \mathrm{m}$ along the minor and major axes. The model calculations used temperature independent thermo-physical properties for the solid phases and the liquid Al phase consistent with literature and summarized in Table I.

The model assumed no contribution from convection in the liquid to the heat transfer. The model accounted for the heat of crystallization of $\mathrm{Al}$, and considered the differences in densities and optical reflectivity for the incident laser radiation of the solid and liquid Al. A composite-model has been used for a phenomenological treatment of the relative contributions of the $\mathrm{Al}$ and amorphous $\mathrm{Si}_{3} \mathrm{~N}_{4}$ layers to heat conduction for a simulated sample geometry comprising a $500 \mu \mathrm{m}$ side length square area of initially solid $\mathrm{Al}$ equivalent to the $160 \mathrm{~nm}$ thick film with the $50 \mathrm{~nm} \mathrm{Si}_{3} \mathrm{~N}_{4}$ support layer and boundary conditions at the perimeter of an infinite heat sink representing the $\mathrm{Si}$ frame. The effective contribution of the nitride layer to 
TABLE I. Thermo-physical Properties used in the COMSOL Simulations. ${ }^{22,23,27-29}$

\begin{tabular}{lcc}
\hline \hline Property & & Unit \\
\hline Thermal conductivity $\mathrm{Al}_{s}$ & $210-230$ & $\mathrm{~W} \mathrm{~m}^{-1} \mathrm{~K}^{-1}$ \\
Thermal conductivity $\mathrm{Al}_{l}$ & 90 & $\mathrm{~W} \mathrm{~m}^{-1} \mathrm{~K}^{-1}$ \\
Density $\mathrm{Al}_{s}$ & 2640 & $\mathrm{~kg} \mathrm{~m}^{-3}$ \\
Density $\mathrm{Al}_{l}$ & 2350 & $\mathrm{~kg} \mathrm{~m}^{-3}$ \\
Density $\mathrm{Si}_{3} \mathrm{~N}_{4}$ & 3100 & $\mathrm{~kg} \mathrm{~m}^{-3}$ \\
Thermal conductivity $\mathrm{Si}_{3} \mathrm{~N}_{4}$ & $8-20$ & $\mathrm{~W} \mathrm{~m}^{-1} \mathrm{~K}^{-1}$ \\
Thermal conductivity Si & 150 & $\mathrm{~W} \mathrm{~m}^{-1} \mathrm{~K}^{-1}$ \\
Heat capacity $\mathrm{Al}_{s}$ & 1000 & $\mathrm{~J} \mathrm{~kg}^{-1} \mathrm{~K}^{-1}$ \\
Heat capacity $\mathrm{Al}_{l}$ & 1095 & $\mathrm{~J} \mathrm{~kg}^{-1} \mathrm{~K}^{-1}$ \\
Heat capacity $\mathrm{Si}_{3} \mathrm{~N}_{4}$ & 700 & $\mathrm{~J} \mathrm{~kg}^{-1} \mathrm{~K}^{-1}$ \\
Heat of fusion $\mathrm{Al}$ & 398 & $\mathrm{~kJ} \mathrm{~kg}^{-1}$ \\
Melting point of Al & 933 & $\mathrm{~K}^{-1}$ \\
Reflectivity $\mathrm{Al}_{s}$ & 0.95 & \\
Reflectivity $\mathrm{Al}_{l}$ & 0.9 & \\
\hline \hline
\end{tabular}

heat conduction after the laser irradiation pulse established an $\mathrm{Al}$ melt pool has been evaluated by varying the fraction of amorphous $\mathrm{Si}_{3} \mathrm{~N}_{4}$ in the simulated composite sample. These calculations indicated that the small thermal conductivity of the amorphous $\mathrm{Si}_{3} \mathrm{~N}_{4}$ resulted in thermal conduction being strongly dominated by the Al thin film during solidification. The experimentally determined metrics used to benchmark the model calculation results included the size of the melt pool of Al, the time delay between delivery of the laser pulse to the onset of directional rapid solidification, the total time to complete solidification, and the temporal evolution of the solid-liquid interface velocity during solidification. ${ }^{27-29}$

\section{RESULTS AND DISCUSSION}

\section{A. Al thin film structure}

The PED TEM-based ACOM data sets displayed in Fig. 2 represent $\mathrm{Al}$ deposited thin films on the $\mathrm{Si}_{3} \mathrm{~N}_{4}$-membranes. The inverse pole figure (IPF) maps for the crystal directions parallel to the film normal (Fig. 2(a)) and the inplane crystal directions parallel to the vertical y-direction (Fig. 2(b)), together with the associated pole figure plots (Fig. 2(d)), reveal a strong preference for alignment of the 111-poles parallel to the film normal direction, i.e., a fibertype thin film 111-growth texture. No preferred orientations are discernible for the crystal directions contained in the plane of the thin film (Figs. 2(b) and 2(d)). Using index quality maps superimposed on virtual BF images give accurate information on grain-size and grain-boundary character ${ }^{30}$ (e.g., Fig. 2(c)), thus delineating clearly the grain boundaries and exhibiting orientation contrast. The Al film grain size has been determined as $160 \mathrm{~nm} \pm 10 \mathrm{~nm}$. Therefore, prior to the pulsed-laser-induced transformation during the DTEM experiments, the $\mathrm{Al}$ thin films exhibited polycrystalline nature with an average grain size about equal to the film thickness with a well-developed 111-type fiber texture along the film normal. These structural characteristics are consistent with standard models for face-centered cubic (fcc) metal thin film growth-related structural evolution for substrate temperatures of $\mathrm{T}=298 \mathrm{~K} \approx 0.32 \mathrm{~T}_{\mathrm{m}}$, where $\mathrm{T}_{\mathrm{m}}=933 \mathrm{~K}$ is the melting point of $\mathrm{Al}^{21}$

\section{B. In-situ DTEM movie mode observations}

The low spatial resolution imaging in the DTEM enabled monitoring of the evolution of the entire melt pool in each of the $20.4 \mu$ s duration in situ experiments that capture the entire transformation sequence (Fig. 3). For melt pools produced by nominally identical laser irradiation pulses incident at the systematically varied distances, $\Delta x$, from the edge of the thick Silicon support frame, effects from the support frame should manifest in different interfacial dynamics during the transformation sequences observed in the experiments. In Fig. 3(a), $\Delta x=50 \mu \mathrm{m}$, the electronopaque region is visible in the top part of frame $(0 \mu \mathrm{s})$ at $t_{\text {img }}=0 \mu \mathrm{s}$, as marked by the yellow lines. The electron pulse train in the MM-DTEM series of Fig. 3 is timed such that the first $50 \mathrm{~ns}$ duration imaging electron pulse, frames (1) of Figs. 3(a)-3(e), annotated as (1), coincides with the peak of the $15 \mathrm{~ns}$ duration laser irradiation pulse on the sample (Fig. 1(c)). The characteristic diffuse oval shape with reduced contrast observed in the first $50 \mathrm{~ns}$ of the transformation sequence $\left(t_{\text {img }}=50 \mathrm{~ns}\right.$, frames (1) in Figs. 3(a)-3(e)) can be attributed to increased thermal diffuse scattering associated with the heating and melting of the Al. It is assumed that melting advances from the surface through the thickness of the film. Prior reports on DTEM experiments using BF imaging and selected area diffraction established that the heating and melting of crystalline metals and alloys induced by the incident laser irradiation result in increased scattering of the electrons in the image forming probe pulse, and thus reduced brightness in BF images (L in frame (4) of Fig. 3(c)) relative
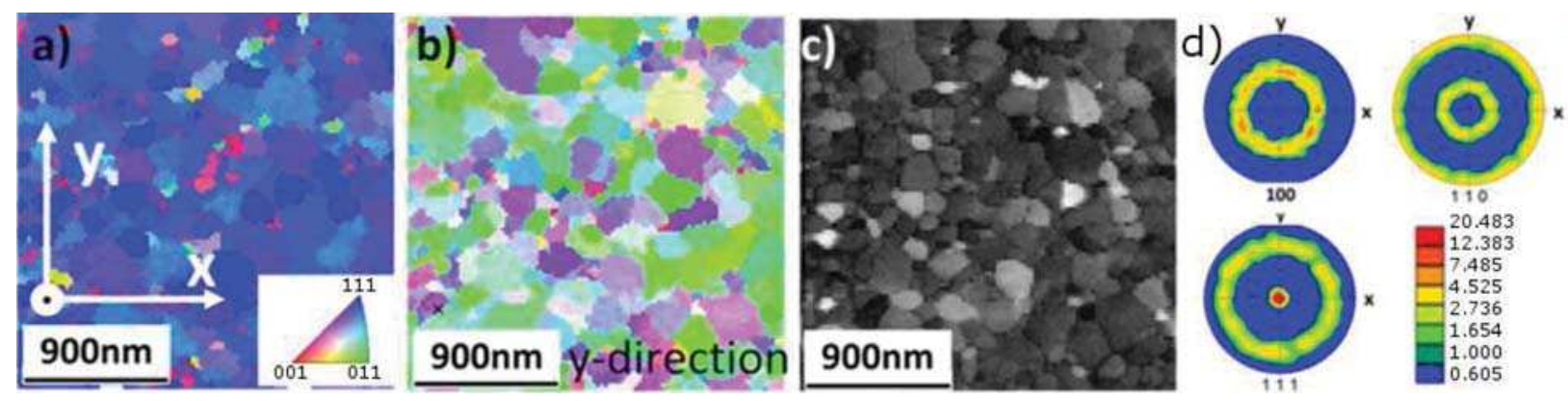

FIG. 2. PED TEM ACOM of as deposited Al film, (a) IPF orientation map of film normal, (b) IPF orientation map for in-plane vertical y-direction, (c) virtual $\mathrm{BF}$ image and index quality map overlay, and (d) the respective $100,110,111$ pole figures. 


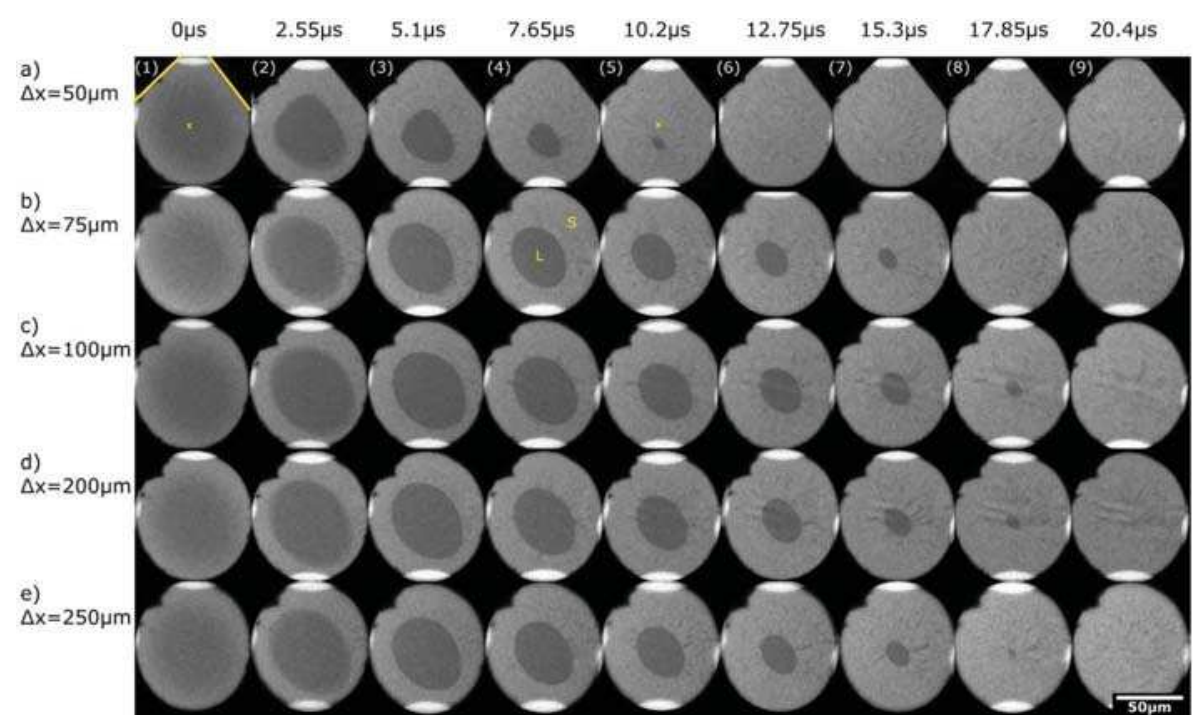

FIG. 3. In-situ DTEM Movie Mode bright field image series from locations (1) to (5) (Fig. 1). (a) $\Delta x=50 \mu \mathrm{m}$, (b) $\Delta x=75 \mu \mathrm{m}, \quad$ (c) $\Delta x=100 \mu \mathrm{m}, \quad$ (d) $\Delta x=200 \mu \mathrm{m}$, and (e) $\Delta x=250 \mu \mathrm{m}$. Each series contains nine individual frames marked (1) to (9). The labels L and $\mathrm{S}$ refer to all-liquid and all-solid regions. See text for further details.

to the brighter contrast levels of surrounding nanocrystalline solid Al (S in frame (4) of Fig. 3(c)). ${ }^{8-10}$ The image series is obtained for $\Delta x=50 \mu \mathrm{m}$ (location (1), Fig. 1(b)) document asymmetries in the melt-pool development from $t_{0}=t_{\text {img }}$ $=0 \mu$ s to $t_{\text {img }}=12.75 \mu$ s (Fig. 3(a)). The close proximity of the Si substrate affects the heat extraction geometry, resulting in notable deviation of the melt pool shape from the elliptical shape of the laser irradiation pulse profile (Fig. $3(\mathrm{a})$, frames (2)-(5)). Solidification rates are considerably higher for the liquid in closer proximity to the $\mathrm{Si}$ support frame than for locations on the opposite side of the melt pool at larger distances from the edge of the electron transparent window. As a result, the last remaining liquid resides at a significantly off-center location relative to the center of the incident elliptical laser irradiation pulse profile (marker $\mathrm{x}$, Fig. 3(a), frames (1) and (5)). In Fig. 3(a), solidification completes after frame (5), $t_{\mathrm{img}}=10.2 \mu \mathrm{s}$, and prior to frame (6), $t_{\text {img }}=12.75 \mu \mathrm{s}$. The transformation sequence shown in Fig. 3(b) has been obtained for $\Delta x=75 \mu \mathrm{m}$ (location (2) in Fig. 1(b)). Melt-pool shape distortions relative to the elliptical shape incident laser irradiation pulse profile are negligible, and the last remaining liquid $\mathrm{Al}$ is observed in frame (7) of Fig. 3(b) at $t_{\text {img }}=15.3 \mu \mathrm{s}$, approximately in the center of the laser irradiated area, and solidification completes prior to frame (8) in Fig. 3(b), $t_{\text {img }}=17.85 \mu \mathrm{s}$. The MM-DTEM series for pulsed laser irradiation at distances $\Delta x$ of $100 \mu \mathrm{m}$, $200 \mu \mathrm{m}$, and $250 \mu \mathrm{m}$ (locations (3) to (5), Fig. 1(b)) is shown in Figs. 3(c)-3(e), respectively. Elliptical melt pools of approximately the same size exhibit essentially identical temporal evolution for these latter locations at distances $\Delta x \geq 100 \mu \mathrm{m}$ from the edge of the $\mathrm{Si}$ support frame. Solidification of the Al completes reproducibly in the symmetry center of the elliptical shape irradiated area after $t_{\text {img }}=17.85 \mu \mathrm{s}$ and prior to $t_{\text {img }}=20.4 \mu \mathrm{s}$ (Figs. 3(c) and 3(e), frames (8) and (9)). Minor qualitative differences can be inferred from the small variations in the fraction of liquid retained in the images obtained at $t_{\text {img }}=17.85 \mu \mathrm{s}$ (frame (8), Figs. 3(c) and 3(e)). However, these latter variations are not systematic with the magnitude of the distance, $\Delta x$, e.g., at $\Delta x=200 \mu \mathrm{m}$ less liquid $\mathrm{Al}$ remains than at $\Delta x=250 \mu \mathrm{m}$ (frame (8), Figs. 3(d) and 3(e)), but correlate with the small but significant differences in the initial melt pool dimensions measured at $t_{\mathrm{img}}=5.1 \mu \mathrm{s}$ (Figs. 3(c)-3(e), frames (3)) and are attributed mainly to the effects of up to $\pm 5 \%$ fluctuations in pulse-to-pulse energy specified for the sample drive laser system used to induce melting at $\mathrm{t}_{0}$. Thus, at distances $\Delta x \geq 100 \mu \mathrm{m}$ from the edge of the electron transparent window, the pulsed laser irradiation induced melting and solidification dynamics for the $\mathrm{Al}$ thin films are reproducible within the spatio-temporal resolution margins of the in situ MM-DTEM experiments.

For the location with $\Delta x=50 \mu \mathrm{m}$, a very large portion of the Gaussian laser pulse photon distribution covers the thick Si frame support (Fig. 1(b), location (1)). For the location with $\Delta x=75 \mu \mathrm{m}$, still a small portion of the laser pulse profile is incident on the Si supported region of the specimen (Fig. 1(b), location (2)). For the locations with $\Delta x \geq 100 \mu \mathrm{m}$ (Fig. 1(b), labels (3)-(5)), the incident laser pulse profiles are entirely contained on the electron transparent window. For the latter locations, the thermal transport from the melt pool is essentially two-dimensional and limited to the Al layer, resulting in symmetric heat extraction rates at opposite side melt pool interfaces during the transformation sequence, and the expected elliptically shaped melt pools are obtained. For the portion of the laser irradiation profile incident on the $\mathrm{Si}$ substrate supported thin film, the thermal transport geometry is three-dimensional, including heat extraction into the $\mathrm{Si}$ substrate along the $\mathrm{z}$-direction through the thickness as well as along the $\mathrm{x}$ - and $\mathrm{y}$-directions within the plane of the thin film. ${ }^{2}$ Therefore, asymmetric thermal transport geometry results in locations where the laser pulse profile significantly overlaps the electron transparent window and the adjacent $\mathrm{Si}$ substrate supported regions. This causes large deviations from the expected elliptical shape of the melt pool and results in an overall smaller melt pool and shorter time to complete solidification observed in MM-DTEM experiments presented in Figs. 3(a) and 3(b) relative to those of Figs. $3(\mathrm{c})-3(\mathrm{e})$.

Hence, a safe distance $(\Delta x, y \geq 100 \mu \mathrm{m})$ from the Silicon support frame needs to be maintained in order to prevent 
artifacts resulting from modifications of the heat extraction geometry and ensure reliable RS transformation rate measurements. For laser irradiation induced melt pools within this region, the heat conduction is approximately two-dimensional, i.e., radially outward from the melt pool perimeter into the surrounding solid, and dominated by the Al layer in the thin film specimens. Numerical modeling of the solidification process supports this conclusion (see Section III D).

For each of the MM-DTEM image series in Fig. 3, a sharp interface between the liquid and surrounding solid $\mathrm{Al}$ (e.g., label L and S in Fig. 3(c), frame c) can be discerned for the times $t_{\text {img }} \geq 5.1 \mu \mathrm{s}$ until completion of solidification. However, this is not the case for image frames acquired at $t_{\text {img }}=2.55 \mu$ s (Fig. 3). Fig. 4 displays the frames (2) from Figs. 3(a)-3(e) at larger magnification. Consistently, the presence of crescent shaped regions exhibiting gray-level contrast intermediate to that of the dark gray liquid (L in Fig. 4(c)) and light gray of the nanocrystalline solid Al thin film ( $\mathrm{S}$ in Fig. 4(c)) can be detected. As a result, the liquid-solid interface appears more diffuse, rendering confident measurements of melt pool size difficult. In Fig. 4(a), $\Delta x=50 \mu \mathrm{m}$, and Fig. 4(b), $\Delta x=75 \mu \mathrm{m}$, these intermediate gray-level contrast areas at the melt pool edge near label 2 are larger than those near label 1 . This is consistent with the asymmetries in the thermal fields resulting from the Si support acting as an effective heat sink. Conversely, for laser pulse incidences at locations with $\Delta x \geq 100 \mu \mathrm{m}$, these regions at opposite sides of the melt pools exhibit the same size. This is consistent with MM-DTEM observations at these locations being essentially free from artifacts introduced by the proximity of the Si support frame (Figs. 4(c) and 4(e)).

These diffuse intermediate-contrast regions along the melt pool perimeter appeared within the first stages, $t_{\text {img }} \leq 2.55 \mu \mathrm{s}$, of the pulsed-laser-induced solid-to-liquid-tosolid transformation sequence of the $\mathrm{Al}$ and vanished over the subsequent $2.55 \mu \mathrm{s}$, prior to onset of $\mathrm{RS}$, recorded at $t_{\text {img }} \geq 5.15 \mu$ s (Fig. 3). We propose that these regions, present in MM-DTEM images at $t_{\text {img }} \leq 2.6 \mu$ s (e.g., Fig. 4), are associated with two-phase regions where liquid and solid coexist during the melting stage of the transformation sequence that precedes the solidification stage. The presence of narrow, $\sim 2 \mu \mathrm{m}$ width, partially melted regions at the perimeter of top-hat profile laser-pulse-induced melt pools in thin films has been inferred in prior reports. ${ }^{31,32}$ The Gaussian laser irradiation pulse would be expected to induce surface melting within sub-nanosecond time scales, followed by melting through the full Al layer thickness in the central region where the highest laser pulse power was delivered, presumably within time frames no longer than several nanoseconds. ${ }^{33,34}$ Subsequently, lateral expansion of the melt pool would involves migration of the liquid-solid interface that initially is inclined through the Al layer thickness. Solidification has been recorded in the MM-DTEM experiments to commence only for $t_{\mathrm{img}} \geq 5.15 \mu \mathrm{s}$ (Fig. 3). During the lateral expansion of the melt pool at shorter times, e.g., $t_{\text {img }}=2.6 \mu \mathrm{s}$, the grains of the solid polycrystalline Al thin film in contact with the liquid would be consumed from their external surfaces towards their centers. Such a process, which would also likely involve melting along some grain boundaries in the nanocrystalline thin film, ${ }^{4,35-37}$ would naturally establish regions of coexisting solid and adjacent liquid $\mathrm{Al}$, since some solid volumes of grains larger than the average grain size would remain at instances when adjacent, initially smaller grains have been fully converted to liquid. Prior reports attributed the presence of partially melted regions at the perimeter of single laser-pulse-induced melt pools in thin films of amorphous Si to the limited sharpness in laser profile. ${ }^{31}$ The projected incidence of the laser pulse on the specimen in the DTEM results in elliptically distorted thermal fields with reduced spatial gradient along the major diameter of the elliptical shape pulse profile. The proposed two-phase regions of coexisting solid and liquid develop to their maximal size in the MM-DTEM frames for $t_{\text {img }}$ $\leq 2.6 \mu$ s within the laser profile segments where the associated thermal field gradients in the Al layer are shallow. These would be the locations where partially melted $\mathrm{Al}$ would be expected to persist longer, and association of these consistently observed crescent-shaped regions of intermediate contrast with partially melted regions, ${ }^{32}$ where for durations of several $\mu \mathrm{s}$ solid and liquid $\mathrm{Al}$ coexist, therefore appears reasonable. Additional higher spatio-temporal resolution, MM-DTEM studies are planned for the future to study this hypothesis.

\section{Determination of crystal growth rates}

$\mathrm{RS}$ of the $\mathrm{Al}$ thin film commences at $2.55 \mu \mathrm{s}<t_{\text {img }}$ $<5.15 \mu$ s upon development of a sharp liquid-solid interface that is smooth, with low curvature and perpendicular to the plane of the film. The transformation interface remains stable against morphological changes, e.g., development of

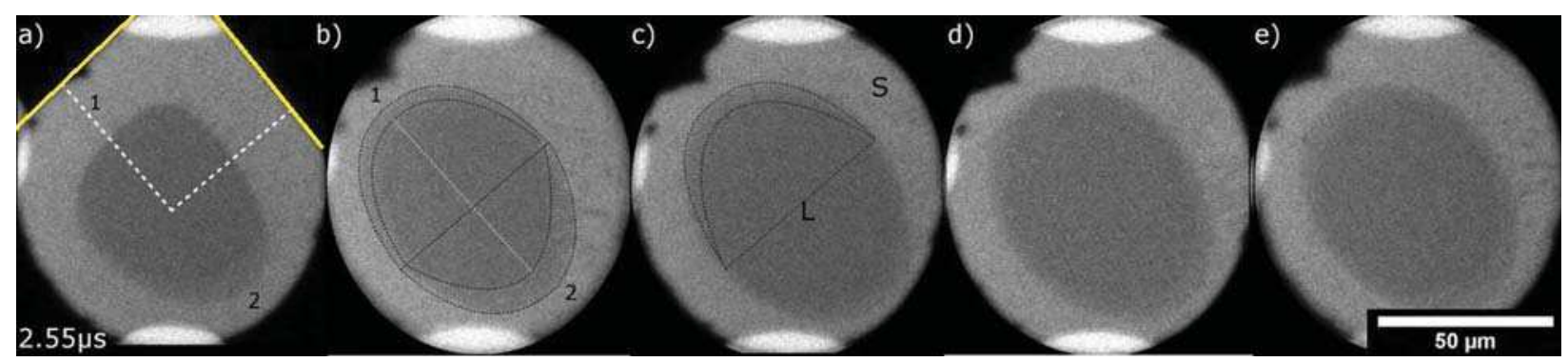

FIG. 4. Collage of frames at $t_{\mathrm{img}}=2.55 \mu \mathrm{s}$ from each image series of Fig. 3. (a) $\Delta x=50 \mu \mathrm{m}$, (b) $\Delta x=75 \mu \mathrm{m}$, (c) $\Delta x=100 \mu \mathrm{m}$, (d) $\Delta x=200 \mu \mathrm{m}$, and (e) $\Delta x=250 \mu \mathrm{m}$. The minimal distance from the melt pool center to the Si support frame is marked in (a). The crescent-shaped regions of diffuse contrast separating the all liquid (label L in (c)) and all solid (label S in (c)) regions are marked in (b) and (c). See text for further details. 
perturbations, during its migration radially towards the center of the melt pools (Fig. 3, $t_{\mathrm{img}} \geq 5.15 \mu \mathrm{s}$ ). This is consistent with prior reports on metal thin film RS and thermally driven, directional crystal growth into a super-heated liquid. $8,20,21,38$ Fig. 5 summarizes results for the RS related transformation rate determination based on quantitative measurements obtained from direct observations of the transformation events recorded in the MM-DTEM experiments (Fig. 3). Figs. 5(a) and 5(b) illustrate the approach for quantitative determination of the solidification rate, using as a representative example the evolution of the melt pool created by the pulsed laser irradiation incidence at $\Delta x=200 \mu \mathrm{m}$. Fig. 5(a) shows the measurements of the radii along the minor, $r_{\max }$, and major, $r_{\min }$, axes obtained for the evolving elliptical melt pool. Prior to the onset of RS, $t_{\mathrm{img}}=2.55 \mu \mathrm{s}$, the major and minor radii of the elliptical melt pool initially differ by about $33 \%$, i.e., $r_{\max } /$ $r_{\min } \approx 1.33 \pm 0.04$, which is consistent with the dimensions of the laser pulse profile within the error of the measurements. The error bars in Fig. 5 represent the variance $\sigma$, which includes the statistical error in the measurement as well as the systematic error introduced due to the fluctuation in laser energy. Both $r_{\max }$ and $r_{\min }$ monotonically decrease with time until the RS transformation completes. The rate of the melt pool radius reduction is faster for $r_{\max }$ than for $r_{\min }$. Hence, depending on their specific location along the elliptically shaped melt pool perimeter, liquid-solid interface segments exhibited a range of solidification velocities. The melt pool area has been determined from measurements of the radii along the major and minor axes of the elliptical pools of liquid $\mathrm{Al}, r_{\text {max }}$, and $r_{\text {min }}$, respectively (e.g., Fig. 5(a)). The average solidification velocity along the entire interface of the elliptical shape melt pools can be obtained from the rate of change of the geometric-mean radius, $\mathrm{r}$, which represents the radius of a circle of equivalent area to that measured for the corresponding elliptical melt pools observed experimentally. The geometric-mean radius data for the melt pool at $\Delta x=200 \mu \mathrm{m}$ are also shown in Fig. 5(a) and fall between the upper and lower bounds given, obtained for $r_{\max }$ and $r_{\min }$.

In order to determine the rapid solidification interface velocity from the rate of change of the melt pool dimensions, both linear regression and second-order polynomial best-fit analyses have been performed for measurement points between $t_{\text {img }}=5.1 \mu \mathrm{s}$ and $t_{\text {img }}=18.4 \mu$ s (e.g., solid and dashed lines in Fig. 5(a)). The measurement points for $t_{\text {img }}=2.55 \mu$ s have been disregarded mainly due to uncertainty in the present interface behavior. The linear regression analyses deliver constant interface migration rates for the RS process. For the example illustrated in Figs. 5(a) and 5(b), $\Delta x=200 \mu \mathrm{m}$, the linear regression based constant solidification interface velocities were determined as $V_{\mathrm{rmin}} \approx 1.6 \mathrm{~m} \mathrm{~s}^{-1}$ and $V_{\mathrm{rmax}} \approx 2.2 \mathrm{~m} \mathrm{~s}^{-1}$
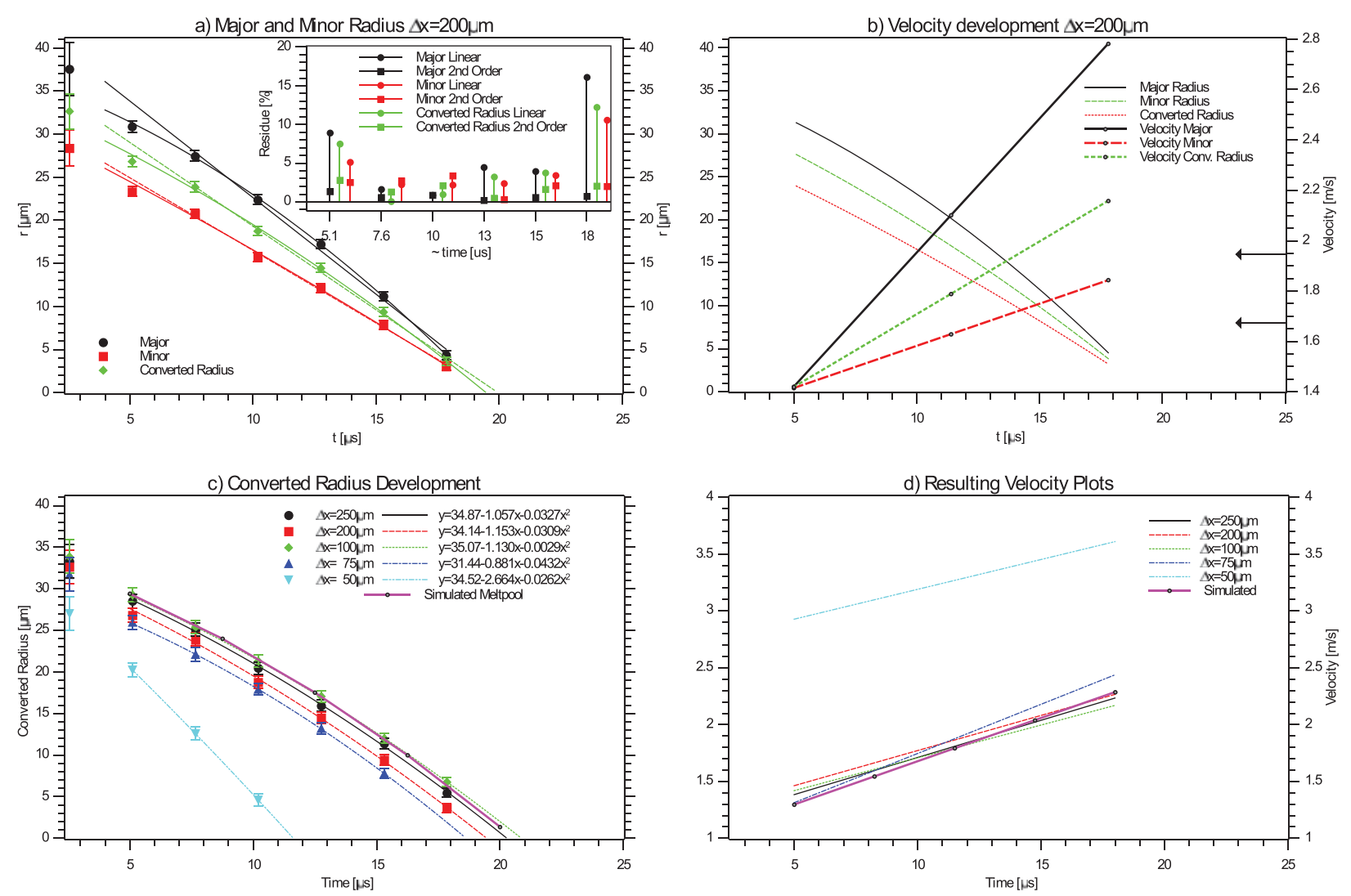

FIG. 5. (a) Evolution of the melt pool radii along the major axis, $r_{\max }$, and minor axis, $r_{\min }$, and for the geometric mean, the converted radius, during rapid solidification in the $\mathrm{Al}$ thin film for $\Delta x=200 \mu \mathrm{m}$, inclusive of linear regression and second-order polynomial best-fit, respectively; (b) RS interface velocity along major and minor radii directions for constant interface accelerations, inclusive of polynomial best fit curves for the respective major, minor, and geometric mean radii; (c) temporal evolution of the respective geometric radius for the experimental data sets for different $\Delta x$ (Fig. 3 ) obtained by numerical modeling calculation (label Simulated); (d) associated solidification velocities. See text for further details. 
along the minor and major axes, respectively, together with an extrapolated time to complete RS of $20.2 \mu$ s (Fig. 5(a)). At first glance, the constant migration rates would appear to be consistent with the experimental observation of RS completion in the interval $17.9 \mu \mathrm{s}<t_{\text {img }}<20.4 \mu$ s (Fig. 3(d)). However, the melt pool retained at $t_{\text {img }}=17.9 \mu$ s for $\Delta x=200 \mu \mathrm{m}$ is considerably smaller than those observed for $\Delta x=100 \mu \mathrm{m}$ and $\Delta x$ $=250 \mu \mathrm{m}$ (Figs. 3(c)-3(e), frames (h)) and would be expected to solidify before the latter two within the $2.55 \mu$ s interval prior to $t_{\mathrm{img}}=20.4 \mu \mathrm{s}$. Hence, the extrapolated solidification time for $\Delta x=200 \mu \mathrm{m}$ of $20.2 \mu \mathrm{s}$ predicted for the case of a constant interface migration rate during $\mathrm{RS}$ is too close to the upper bound of the experimentally determined interval $17.9 \mu \mathrm{s}<t_{\text {img }}<20.4 \mu \mathrm{s}$ for completion of the RS process. Furthermore, it consistently initiates in the early stage and in the late stage of solidification overestimated and at intermediate stages underestimated the experimentally measured melt pool radii. These characteristic deviations from a linear rate of change for the radii of the melt pools during the RS stage indicate that the crystallization front interface migration rates may in fact not be constant but rather accelerate during RS. Using weighted $\left(1 / \sigma^{2}\right)$ second-order polynomial best-fit functions, equivalent to the simple case of constant acceleration of the solidification interface, delivered improved match with the experimentally measured radii for the evolving melt pools for $t_{\text {img }} \geq 5.15 \mu$ s (e.g., Fig. 5(a)). The insert in Fig. 5(a) shows the residuals between measurements, the linear regression fit (circles), and the polynomial fit (squares). For early times, $\mathrm{t} \sim 5 \mu \mathrm{s}$, the polynomial fit reduces the residual by one order of magnitude for the major axis, and by a factor of two for the geometric-mean and the minor radius. For times between $\mathrm{t} \sim 7 \mu \mathrm{s}$ and $\mathrm{t} \sim 10 \mu \mathrm{s}$, the linear regression fit and the polynomial fit deliver comparable residuals. Near the end of the solidification processes between $\mathrm{t} \sim 13 \mu$ s and $\mathrm{t} \sim 18 \mu \mathrm{s}$, the second-order polynomial fit shows the most significant reductions in the residual relative to the linear regression. Furthermore, the polynomial fit provided a reduced extrapolated time required for completion of solidification, for example, with $\Delta x=200 \mu \mathrm{m}$ from $20.2 \mu$ s to $19.3 \mu$ s, now well within the experimentally determined interval $17.9 \mu \mathrm{s}<t_{\text {img }}<20.4 \mu$ s (Figs. 5(a) and 5(b)). Fig. 5(b) displays the polynomial best-fit functions obtained for the major and minor axes radii and the associated accelerating solidification interface velocities during RS for the minor and major radii of the melt pool example with $\Delta x=200 \mu \mathrm{m}$. The minor and major radii provide a lower and upper bound to the experimentally observed RS velocities $V_{\text {rmin }}$ and $V_{\text {rmax }}$, and increase from $V_{\text {rmin }} \approx 1.4 \mathrm{~m} \mathrm{~s}^{-1}$ and $V_{\text {rmax }} \approx 1.4 \mathrm{~m} \mathrm{~s}^{-1}$ to reach $V_{\text {rmin }} \approx 2.0 \mathrm{~m} \mathrm{~s}^{-1}$ and $V_{\text {rmax }} \approx$ $3.1 \mathrm{~m} \mathrm{~s}^{-1}$, respectively, for the melt pool at $\Delta x=200 \mu \mathrm{m}$ during the RS process. The arrows in Fig. 5(b) mark the equivalent constant velocities of interface segments for migration along the minor $\left(1.6 \mathrm{~m} \mathrm{~s}^{-1}\right)$ and major $\left(2.2 \mathrm{~m} \mathrm{~s}^{-1}\right)$ radii. The ratio of the upper-bound to lower-bound $\mathrm{RS}$ facilitating interface velocities, e.g., $V_{\text {rmax }} / V_{\text {rmin }} \approx 2.7 / 2.0=1.35$ for the case of interface migration with constant acceleration and also for the constant interface velocity (e.g., 2.22/ $1.64=1.35)$, simply scale with the initial dimensions of the elliptical melt pools, $r_{\max } / r_{\min } \approx 1.33 \pm 0.04$. The area changes of the elliptical melt pools obtained for the laser irradiation incidence at locations with different values of $\Delta x$ are represented by the changes of the respective geometricmean radius, r, with time in Fig. 5(c). All melt pools monotonically reduce size for $t_{\text {img }}>2.6 \mu \mathrm{s}$, consistent with solidification by directional crystal growth (Fig. 5). The melt pool at $\Delta x=50 \mu \mathrm{m}$ is located closer to the substrate support frame (location 1, Fig. 1), which changes the heat extraction geometry and leads to the smallest and asymmetric starting melt pool dimensions. This ultimately results in a RS process with the highest interface migration rate and the shortest time to completion (Fig. 5(c)). For the laser incidence located at $\Delta x=75 \mu \mathrm{m}$, a melt pool with initial radius $\mathrm{r}=32 \mu \mathrm{m}$, only slightly smaller than those for $\Delta x \geq 100 \mu \mathrm{m}$ with $33 \mu \mathrm{m} \leq \mathrm{r} \leq 34.4 \mu \mathrm{m}$, resulted at $t_{\text {img }}=2.6 \mu \mathrm{s}$ (Fig. $5(\mathrm{c})$ ). Using the second-order polynomial best-fit functions for the geometric-mean radii, the solidification velocity evolutions shown in Fig. 5(d) have been obtained. Within the uncertainty associated with the MM-DTEM experiments, the melt pool size evolution rates are identical for locations with $\Delta x>75 \mu \mathrm{m}$ (Fig. 5(d)). During the RS stage, $t_{\text {img }} \geq 5.15 \mu \mathrm{s}$, the average solidification interface section along the perimeter of the melt pools migrated at a constantly accelerating velocity, which increased from about $1.35 \mathrm{~m} \mathrm{~s}^{-1}$ to $2.5 \mathrm{~m}$ $\mathrm{s}^{-1}$, with an average of $1.9 \mathrm{~m} \mathrm{~s}^{-1}$, for locations with $\Delta x \geq$ $100 \mu \mathrm{m}$ on the electron transparent window (Fig. 5(d)). The effects of the proximity to the Si substrate produce not just smaller size and asymmetric shape melt pools (Figs. 3 and $5(\mathrm{c})$ ), but also faster RS interface migration rates. For the location with $\Delta x=50 \mu \mathrm{m}$ crystallization, we measured an interface velocity in the range of $2.9 \mathrm{~m} \mathrm{~s}^{-1}$ to $3.3 \mathrm{~m} \mathrm{~s}^{-1}$ and with an average of $3.1 \mathrm{~m} \mathrm{~s}^{-1}$ (Fig. 5(d)). The MM-DTEM based in situ observations enabled measurements of changes in the liquid-solid interface migration rate, e.g., accelerations and not just average velocity, as well as detection of the initial melting stage prior to the onset of crystal growth during the rapid solidification. The latter was associated with durations longer than $2.55 \mu \mathrm{s}$ and shorter than $5.1 \mu \mathrm{s}$, based on the MM-DTEM measurements, and lasted $4.2 \mu \mathrm{s}$ according to the model calculations (see Section IIID.). Experiments that utilize the total time elapsed after the delivery of the ns-laser pulse to detection of completion of solidification would inherently neglect to account for the substantial duration of melting processes in the $\mathrm{Al}$ prior to onset of the actual RS crystal growth. Given a total time of $18 \mu \mathrm{s}-20 \mu \mathrm{s}$ required for the melting-solidification sequence, neglecting to take into account the $\sim 3-5 \mu$ s delays prior to RS onset would result in systematically underestimating the average solidification velocity by about $20 \%-25 \%$. The MM-DTEM experiments performed here for $\mathrm{Al}$ within the central region of approximate dimensions $300 \mu \mathrm{m} \times 300 \mu \mathrm{m}$ of the electron transparent window exhibit identical initial melt pool size and shape, duration of the melting stage, and crystal growth rates during the RS stage of the laser induced transformation sequences. The accelerating RS interface sections migrate at considerably different rates for different locations along the perimeter of the melt pools, i.e., $V_{\text {rmax }} \approx 1.35 V_{\text {rmin }}$ have been measured. 


\section{Numerical modeling of Al thin-film rapid solidification}

Numerical modeling of the melt pool evolution has been performed for pulsed laser incidence located centrally, i.e., for $\Delta x=250 \mu \mathrm{m}$, in a $500 \mu \mathrm{m} \times 500 \mu \mathrm{m}$ wide area of $\mathrm{Al}$ thin film equivalent to those used in the MM-DTEM experiments. Considering only the heat conduction laterally within the thin film, we calculated the thermal field evolution in the specimen after delivery of a laser pulse. The model calculations were constrained to adjustments of the total energy delivered by the laser pulse for a profile matching the experimentally determined size of the irradiated elliptical area on the specimen, and the effective thermal conductivity of the amorphous $\mathrm{Si}_{3} \mathrm{~N}_{4}$ supported $\mathrm{Al}$ thin film. Calculations that delivered excellent matches to the experimentally determined metrics of initial melt pool dimension in terms of $r_{\max }=37 \mu \mathrm{m}, r_{\min }=27 \mu \mathrm{m}$, and other experimental benchmark metrics, i.e., the total area and temporal evolution of melt pool size, resultant solidification velocity, and total time to complete solidification, have been obtained using laser energy of $85 \mu \mathrm{J}$ for films with $160 \mathrm{~nm}$ thick Al layers and $45 \mu \mathrm{J}$ for films with $80 \mathrm{~nm} \mathrm{Al}$ layers with effective thermal conductivities of $210 \mathrm{~W} \mathrm{~K}^{-1} \mathrm{~m}^{-1}$ for the solid and $90 \mathrm{~W}$ $\mathrm{K}^{-1} \mathrm{~m}^{-1}$ for the liquid, respectively. Using values of the effective thermal conductivity of the solid, which represents the combined contributions to heat conduction from the $\mathrm{Si}_{3} \mathrm{~N}_{4}$ and $\mathrm{Al}$ layers, that lie within the range of thermal conductivity values reported for solid $\mathrm{Al}, 205-230 \mathrm{~W} \mathrm{~K}^{-1} \mathrm{~m}^{-1}$ implies that the $\mathrm{Al}$ heat conduction dominated during the laser pulse induced transformation sequence. The calculations that matched the experimental benchmark metrics within the constraints imposed on the laser pulse showed maximum temperatures at the center of the superheated liquid $\mathrm{Al}$ of $1365 \mathrm{~K}$ and dwell times associated with melting prior to onset of solidification of $4.2 \mu$ s (e.g., Fig. 6). Fig. 6 shows two example thermal field evolution calculations equivalent to observations at $t_{\text {img }}=2.6 \mu$ s prior to the onset

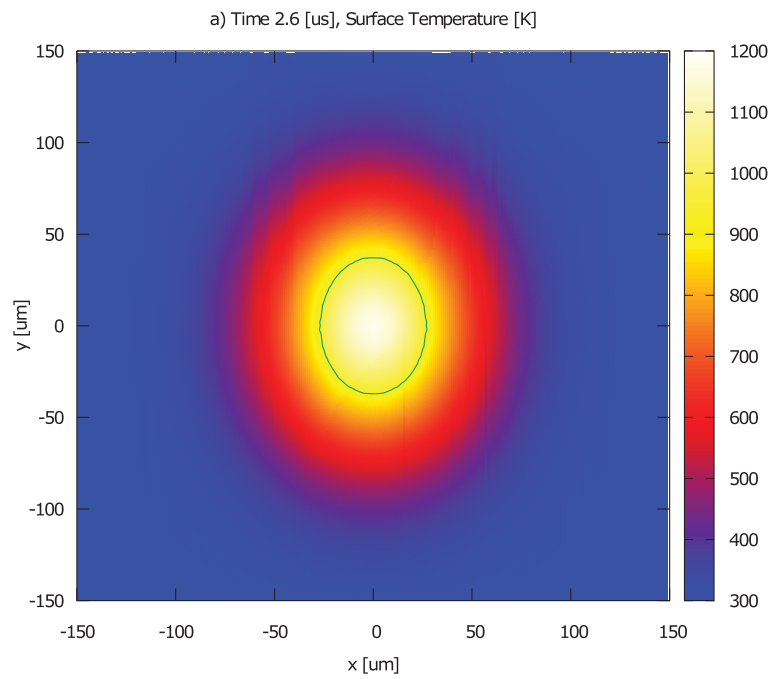

of the RS stage and $t_{\text {img }}=18 \mu \mathrm{s}$ just prior to completion of $\mathrm{RS}$. The Al melt cooled at rates on the order of $10^{7} \mathrm{~K} \mathrm{~s}^{-1}$ and regions of the $\mathrm{Al}$ thin film located outside of the Gaussian elliptical shape laser pulse profile with $r_{\max }=94 \mu \mathrm{m}$ and $r_{\text {min }}=68 \mu \mathrm{m}$ experienced minimal heating for the $17.9 \mu \mathrm{s}$ duration of the transformation sequence (Fig. 6). Akin to the experimental measurements, the calculation results of the melt pool size evolution exhibited consistent deviations from linear behavior, e.g., regarding overestimating the total time to complete solidification, which could be mediated by applying second-order polynomial best-fit procedures. Hence, the case of interface migration with a constant acceleration also provides better agreement with the numerical modeling based calculations. The numerical modeling results for the evolution of the melt pool size and velocity during $\mathrm{RS}$ of the $160 \mathrm{~nm}$ thick Al thin film are included in Figs. 5(c) and 5(d). The geometric-mean radius related metrics, which represent the behavior of average interface segment, are used here for illustrating a comparison of the model calculation results with the five different experimental data sets. While, of course inherently not predictive, the qualitative and quantitative agreements of the numerical modeling results with the experimental measurements support the conclusion that for a good approximation, the solid-liquid interface velocity accelerates during RS and the associated melt pool evolution is dominated by the thermal transport from the superheated Al radially outward into the surrounding solid. Since the thermal conductivity of the solid $\mathrm{Al}$ exceeds that of liquid $\mathrm{Al}$ significantly, it appears reasonable to propose that the migration rate of the solid-liquid interface is limited by the twodimensional heat-flow of the excess heat of fusion evolved at the interface and the thermal conductivity of the solid surrounding the melt.

\section{SUMMARY AND CONCLUSIONS}

In summary, in situ dynamic transmission electron microscopy studies of rapid solidification in polycrystalline

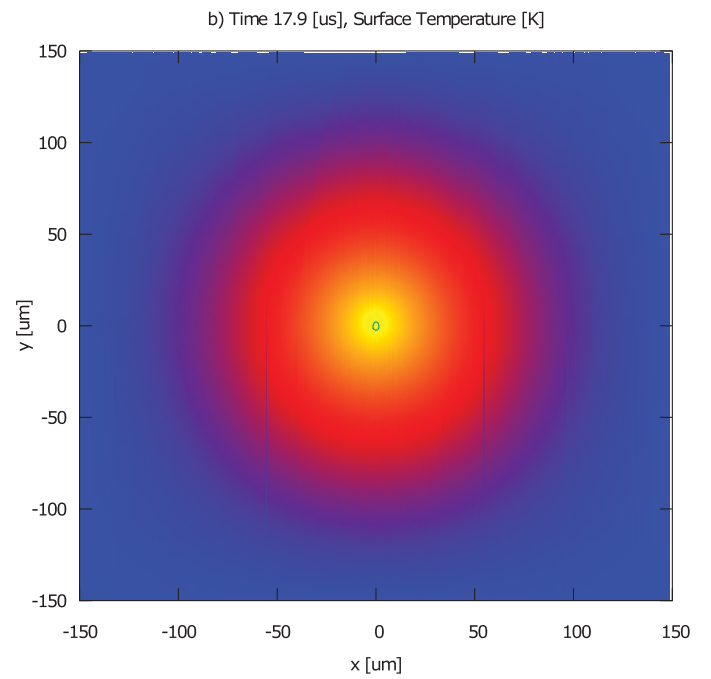

FIG. 6. Numerical simulation based calculations of thermal field evolutions for laser pulse induced melt pools (solid line ellipse) in Al thin film for central location, $\Delta x=250 \mu \mathrm{m}$, for the central $300 \mu \mathrm{m} \times 300 \mu \mathrm{m}$ section on the $500 \mu \mathrm{m} \times 500 \mu \mathrm{m}$ electron transparent window; example visualizations of the thermal fields at (a) $t_{\mathrm{img}}=2.6 \mu \mathrm{s}$ and (b) $t_{\mathrm{img}}=17.9 \mu \mathrm{s}$. 
Al have been performed in Movie-Mode operation using windowed membrane TEM grids and revealed changes in crystal growth rates due to effects from differences in the heat extraction geometry. Quantification of the dynamic behavior of rapid solidification that is free from artifacts and reproducible can be achieved by controlling the position of the solidification experiment on the TEM grid, thus ensuring that the heat extraction remains the same during multiple experiments. The high temporal resolution in situ TEM experiments permitted discovery of regions of coexisting solid and liquid $\mathrm{Al}$ at the perimeter of the melt pool that persisted for several microseconds prior to the onset of directional crystal growth during rapid solidification. This is attributed to distorted thermal fields with reduced spatial gradient along the major diameter of the elliptical melt pool. The in situ TEM experiments confirmed a range of solidification front velocities for different interface segments along the perimeter of the elliptical melt pool, with a maximum and minimum velocity along the major and minor axes of the melt pool, respectively. This is a consequence of heat extraction due to variations in the local curvature of the solid-liquid interface. Using several metrics obtained directly from the in situ MM-DTEM experiments for constraining inputs and for benchmarking results of finite-element modeling calculations enabled determination of the temperature evolutions during the pulsed laser induced RS transformation of $\mathrm{Al}$ thin films. Experiments and matching calculations showed that the solid-liquid interface accelerated during the rapid solidification facilitated crystal growth. Melt pool evolution was dominated by thermal transport from the superheated $\mathrm{Al}$ and the heat of crystallization evolving at the solid-liquid interface radially outward into the surrounding solid, indicating that the migration rate of the solid-liquid interface was limited by the thermal transport properties of the surrounding solid.

\section{ACKNOWLEDGMENTS}

The authors gratefully acknowledge support for this work from the U.S. Department of Energy and the U.S. National Science Foundation. This work has been performed under the auspices of the U.S. Department of Energy by Lawrence Livermore National Laboratory (LLNL) under Contract No. DE-AC52-07NA27344. Activities and personnel at LLNL were supported by the U.S. Department of Energy, Office of Science, Office of Basic Energy Sciences, Division of Materials Sciences and Engineering under FWP SCW0974. Activities and personnel at the University of Pittsburgh received support from the National Science Foundation, Division of Materials Research, Metals \& Metallic Nanostructures program through Grant No. DMR 1105757.

${ }^{1}$ W. E. King, G. H. Campbell, A. Frank, B. Reed, J. F. Schmerge, B. J. Siwick, B. C. Stuart, and P. M. Weber, "Ultrafast electron microscopy in materials science, biology, and chemistry," J. Appl. Phys. 97, 111101 (2005).

${ }^{2}$ A. Kulovits, R. Zhong, J. Wiezorek, and J. Leonard, “Electron microscopy of geometrically confined copper thin films after rapid lateral solidification,” Thin Solid Films 517, 3629-3634 (2009).
${ }^{3}$ R. Zhong, A. Kulovits, J. Wiezorek, and J. Leonard, "Four-zone solidification microstructure formed by laser melting of copper thin films," Appl. Surf. Sci. 256, 105-111 (2009).

${ }^{4}$ U. Dahmen, S. Hagege, F. Faudot, T. Radetic, and E. Johnson, "Observations of interface premelting at grain-boundary precipitates of $\mathrm{Pb}$ in Al,” Philos. Mag. 84, 2651-2662 (2004).

${ }^{5}$ Z. Shan, E. Stach, J. Wiezorek, J. Knapp, D. Follstaedt, and S. Mao, "Grain boundary-mediated plasticity in nanocrystalline nickel," Science 305, 654-657 (2004).

${ }^{6} \mathrm{P}$. Palanisamy, M. de Jong, M. Asta, and J. M. Howe, "Examination of the electronic structure of crystalline and liquid al versus temperature by in situ electron energy-loss spectroscopy (EELS)," Micron 76, 14-18 (2015).

${ }^{7}$ J. M. Howe, H. Mori, and Z. L. Wang, "In situ high-resolution transmission electron microscopy in the study of nanomaterials and properties," MRS Bull. 33, 115-121 (2008).

${ }^{8}$ A. Kulovits, J. M. Wiezorek, T. LaGrange, B. W. Reed, and G. H. Campbell, "Revealing the transient states of rapid solidification in aluminum thin films using ultrafast in situ transmission electron microscopy," Philos. Mag. Lett. 91, 287-296 (2011).

${ }^{9}$ T. LaGrange, G. H. Campbell, B. Reed, M. Taheri, J. B. Pesavento, J. S. Kim, and N. D. Browning, "Nanosecond time-resolved investigations using the in situ of dynamic transmission electron microscope (DTEM)," Ultramicroscopy 108, 1441-1449 (2008).

${ }^{10}$ J. S. Kim, T. LaGrange, B. W. Reed, M. L. Taheri, M. R. Armstrong, W. E. King, N. D. Browning, and G. H. Campbell, "Imaging of transient structures using nanosecond in situ tem," Science 321, 1472-1475 (2008).

${ }^{11}$ A. Kulovits, J. Wiezorek, T. LaGrange, B. Reed, and G. Campbell, "In situ transmission electron microscopy of rapidly solidifying metals and alloys," Microsc. Microanal. 17, 506-507 (2011).

${ }^{12}$ T. LaGrange, B. W. Reed, M. K. Santala, J. T. McKeown, A. Kulovits, J. M. Wiezorek, L. Nikolova, F. Rosei, B. J. Siwick, and G. H. Campbell, "Approaches for ultrafast imaging of transient materials processes in the transmission electron microscope," Micron 43, 1108-1120 (2012).

${ }^{13}$ J. T. McKeown, T. LaGrange, B. Reed, G. Campbell, A. Kulovits, and J. Wiezorek, "Ultrafast imaging of rapid alloy solidification in al-cu thin films," Microsc. Microanal. 18, 602-603 (2012).

${ }^{14}$ J. T. McKeown, A. K. Kulovits, C. Liu, K. Zweiacker, B. W. Reed, T. LaGrange, J. M. Wiezorek, and G. H. Campbell, "In situ transmission electron microscopy of crystal growth-mode transitions during rapid solidification of a hypoeutectic Al-Cu alloy," Acta Mater. 65, 56-68 (2014).

${ }^{15}$ G. H. Campbell, J. T. McKeown, and M. K. Santala, "Time resolved electron microscopy for in situ experiments," Appl. Phys. Rev. 1, 041101 (2014).

${ }^{16}$ K. Zweiacker, C. Liu, J. T. McKeown, T. LaGrange, B. W. Reed, G. H. Campbell, and J. M. Wiezorek, "Crystal growth mode changes during pulsed laser induced rapid solidification in nanoscale thin films of $\mathrm{Al}-\mathrm{Cu}$ eutectic," Microsc. Microanal. 20, 1662-1663 (2014).

${ }^{17}$ T. LaGrange, B. W. Reed, and D. J. Masiel, "Movie-mode dynamic electron microscopy," MRS Bull. 40, 22 (2015).

${ }^{18}$ J. T. McKeown, K. Zweiacker, C. Liu, D. R. Coughlin, A. J. Clarke, J. K. Baldwin, J. W. Gibbs, J. D. Roehling, S. D. Imhoff, P. J. Gibbs, D. Tourret, J. M. K. Wiezorek, and G. H. Campbell, "Time-resolved in situ measurements during rapid alloy solidification: Experimental insight for additive manufacturing," JOM 68, 985-999 (2016).

${ }^{19} \mathrm{~K}$. Zweiacker, "In-situ TEM investigation of rapid solidification of aluminum and aluminum copper alloys," Ph.D. dissertation (University of Pittsburgh, 2015).

${ }^{20}$ A. Kulovits, G. Facco, and J. Wiezorek, "Grain size determination in nano-scale polycrystalline aggregates by precession illumination-hollow cone dark field imaging in the transmission electron microscope," Mater. Character. 63, 17-26 (2012).

${ }^{21} \mathrm{C}$. Thompson, "Structure evolution during processing of polycrystalline films," Ann. Rev. Mater. Sci. 30, 159-190 (2000).

${ }^{22}$ H. Shanks, P. Maycock, P. Sidles, and G. Danielson, "Thermal conductivity of silicon from 300 to 1400 k, ' Phys. Rev. 130, 1743 (1963).

${ }^{23}$ C. Glassbrenner and G. A. Slack, "Thermal conductivity of silicon and germanium from $3 \mathrm{k}$ to the melting point," Phys. Rev. 134, A1058 (1964).

${ }^{24}$ Y. Idell, G. Facco, A. Kulovits, M. Shankar, and J. Wiezorek, "Strengthening of austenitic stainless steel by formation of nanocrystalline $\gamma$-phase through severe plastic deformation during two-dimensional linear plane-strain machining," Scr. Mater. 68, 667-670 (2013).

${ }^{25} \mathrm{H}$. Hu and S. A. Argyropoulos, "Mathematical modelling of solidification and melting: a review," Modell. Simul. Mater. Sci. Eng. 4, 371 (1996). 
${ }^{26} \mathrm{~N}$. Shamsundar and E. Sparrow, "Analysis of multidimensional conduction phase change via the enthalpy model," J. Heat Transf. 97, 333-340 (1975).

${ }^{27}$ R. Powell, C. Y. Ho, and P. E. Liley, "Thermal conductivity of selected materials," Technical Report, DTIC Document, 1966.

${ }^{28}$ T. S. Srivatsan, T. Sudarshan, and E. Lavernia, "Processing of discontinuously-reinforced metal matrix composites by rapid solidification," Prog. Mater. Sci. 39, 317-409 (1995).

${ }^{29} \mathrm{X}$. Zhang and C. P. Grigoropoulos, "Thermal conductivity and diffusivity of free-standing silicon nitride thin films," Rev. Sci. Instrum. 66, 1115-1120 (1995).

${ }^{30} \mathrm{E}$. Rauch and M. Vron, "Automated crystal orientation and phase mapping in $\{$ TEM $\}$," Mater. Character. 98, 1-9 (2014).

${ }^{31}$ J. P. Leonard, "Determination of the absolute fluence profile in pulsed laser processing using melt-induced phase changes in an amorphous silicon thin film," Rev. Sci. Instrum. 77, 053101 (2006).

${ }^{32}$ J. M. Wiezorek, J. T. McKeown, K. Zweiacker, T. LaGrange, B. W. Reed, C. Liu, and G. H. Campbell, "Capturing dynamics of pulsed laser induced melting and rapid solidification in aluminum polycrystals with nanoscale temporal resolution in-situ TEM," Microsc. Microanal. 20, 1582-1583 (2014).

${ }^{33}$ B. J. Siwick, J. R. Dwyer, R. E. Jordan, and R. D. Miller, "An atomiclevel view of melting using femtosecond electron diffraction," Science 302, 1382-1385 (2003)

${ }^{34}$ J. Chen, W.-K. Chen, J. Tang, and P. M. Rentzepis, "Time-resolved structural dynamics of thin metal films heated with femtosecond optical pulses," Proc. Natl. Acad. Sci. 108, 18887-18892 (2011).

${ }^{35}$ R. Zivieri, G. Santoro, and V. Bortolani, "Premelting of the al (110) surface from a local perspective," Phys. Rev. B 62, 9985 (2000).

${ }^{36}$ Y. Mishin, W. Boettinger, J. Warren, and G. McFadden, "Thermodynamics of grain boundary premelting in alloys. I. Phase-field modeling," Acta Mater. 57, 3771-3785 (2009).

${ }^{37}$ Y. Li, L. Wang, B. Li, F. Zhao, J. Zhu, S. Luo et al., "Thermally driven grain boundary migration and melting in Cu," J. Chem. Phys. 142, 054706 (2015).

${ }^{38}$ D. A. Porter, K. E. Easterling, and M. Sherif, Phase Transformations in Metals and Alloys (Revised Reprint) (CRC Press, 2009). 